\title{
PHYSICAL INACTIVITY AS ONE OF THE CHRONIC DISEASE RISK FACTORS AMONG HIGH SCHOOL LEARNERS IN PUBLIC SCHOOLS IN A LOCAL COMMUNITY IN SOUTH AFRICA
}

\author{
José M. FRANTZ \\ Department of Physiotherapy, University of the Western Cape, Bellville, \\ Republic of South Africa
}

\begin{abstract}
This study aimed to determine the physical activity levels and existence of risk factors associated with chronic diseases of lifestyle among high school learners. A crosssectional research design was used to obtain information about physical activity levels from 951 learners from two high schools in a local community in the Western Province of South Africa. Physical activity levels were obtained using the KUOPIO Ischaemic Heart Disease 24-hour physical activity record over a seven-day period. Anthropometrical and blood pressure measurements as well as behaviours including cigarette smoking and alcohol use were recorded as risk factors for chronic diseases of lifestyle. Statistical analyses were performed using the Statistical Package for Social Science (2000). Risk factors were identified as obesity, physical inactivity, smoking and hypertension. Variance of analysis (ANOVA) was used to statistically determine differences in groups. The results indicated that $32 \%$ of the learners were classified as being physically inactive and that $21 \%$ engaged in health risk behaviours. In addition, 35\% of the learners had more than one risk factor for chronic diseases of lifestyle present. Since cardiovascular risk factors have been shown to persist into adulthood, health professionals should assume some responsibility for the prevention, detection, and intervention relevant to cardiovascular risk factors in adolescents.
\end{abstract}

Key words: Physical inactivity; Learners; Disease; Obesity; Risk factors; Lifestyle.

\section{INTRODUCTION}

The burden of chronic diseases of lifestyle is a key impediment to social and economic progress as these diseases have become the leading cause of death and disability worldwide (Alberti, 2001). The World Health Report (2000) estimated that chronic diseases of lifestyle accounted for $60 \%$ of global mortality and $43 \%$ of the global burden of disease. In order to prevent the epidemic of chronic diseases of lifestyle, both the immediate and the root causes of these diseases must be identified (Canon, 2001). Physical inactivity is one of the immediate causes of chronic diseases and one that is modifiable. In Canada, approximately $3 \%$ of the total direct health care costs, i.e. over $\$ 2$ billion, can be attributed to physical inactivity (Katzmarzyk et al.,1998).

The World Health Organisation (WHO) identified physical inactivity as a threatening public health issue worldwide and subsequently introduced the STEPwise approach to monitor the emergence of non-communicable diseases (WHO, 2003). The STEPS approach is based on sequential levels of surveillance of different aspects of non-communicable disease. Within this 
approach the most common non-communicable diseases and their established behavioural and physiological risk factors that meet criteria for surveillance are identified. The modifiable behavioural risk factors include smoking, drinking alcohol, and physical inactivity. In addition, the physiological risk factors include excess body fat (obesity), high blood pressure, abnormal blood glucose and abnormal blood lipids.

Prevention through risk factor focused intervention requires population specific data on risk factors so that priorities can be appropriately set. Insufficient physical activity data in children and adolescents has also been identified as a concern. According to Lambert et al. (2001), South African data on the prevalence of physical inactivity, especially among the youth, is limited. The Birth to Twenty Study (Birth to Twenty, 2002) and the THUSA BANA study (Underhay et al., 2003) are two of the main studies relating to physical inactivity in South Africa that report on South African youth. These studies reported that more than $40 \%$ of young people do not participate in regular physical activity. This information was part of a bigger study of which a section focused on physical activity levels. In addition, a study by Coetzee and Underhay (2003) reported that adolescents from as early as 13 years of age take part in health risk behaviours which include cigarette smoking, alcohol and drugs, unsafe sexual behaviour and physical inactivity. An underlying premise for the promotion of physical activity in youth is that it may persist through adulthood and lead to a healthy lifestyle (Brunton et al., 2003). Physical activity levels among young people have raised cause for concern. In America, the 1995 school-based youth risk behaviour study indicated a 10.4\% prevalence of inactivity (Centre for Disease Control and Prevention, 1996). In Australia, it was found that among the young people 10\% were inactive (Baumann \& Campbell, 2001). According to Bouchard et al. (1990) the general model underlying most research on the relationships among physical activity, physical fitness and health is that physical fitness is one of the mediators of the effects of physical activity on health outcomes. Thus, to develop effective interventions to assist positive health outcomes, one needs to evaluate the physical activity patterns and health habits of the youth, as evidence indicates that these associations track into adulthood.

The study population for the current study included all young people who attended high school in a particular local community in South Africa. This community was chosen based on its representivity of the previously disadvantaged group in the Western Cape, South Africa. The sample included two of the high schools in the community. The objectives of the study were to describe the physical activity levels of youth aged 13 to 18 years and to examine the association between physical activity levels and other risk factors for chronic diseases of lifestyle.

\section{METHODS}

\section{Research design}

The research described in this article forms part of a larger doctoral study conducted in a local community in the Western Province. A cross-sectional research design was used. Nine hundred and fifty-one (951) high school learners aged 13 to 18 years selected from the secondary schools in the selected community were included in the sample. Data were collected over a period of 12 months. 


\section{Subjects}

The learners were conveniently selected and following informed consent from the school, parents and the learners, only two of the four high schools decided to participate in the study. The 951 learners in the study consisted of 477 males and 474 females. The mean age for these learners was 15.2 years $(\mathrm{SD}=1.5)$.

\section{Test materials}

Data were obtained using a questionnaire that contained three sections. Information obtained from the questionnaire included (1) socio-demographic characteristics of the participants (age, family income, parents' educational level and occupation); (2) self-reported daily habitual activity level over seven days and (3) objective measurement of health related physical fitness levels (Fitnessgram). The KIHD 24 hours physical activity record was adapted and used in the study as it was found to be reliable in measuring activities in a short period of recall (Baranowski, 1988). The daily physical activity report was divided into 13 activities which included sitting, grooming, walking for 15 minutes, studying, gardening, household chores and sporting activities. For analysis it was further classified into four categories as reported by the Surgeon General Report (1996). These included sedentary activities, light intensity activities, moderate intensity activities and vigorous intensity activities. Information regarding current smoking and drinking of alcohol habits for the previous week was also recorded. The instrument was pre-tested on 20 learners for content validity and to ensure that the learners understood what was expected of them. The instrument was also tested one week apart on this group to check for test-retest reliability and yielded a Chronbachs alpha of .82. These learners did not form part of the final study sample.

Anthropometrical and blood pressure measurements that were included from the battery of physical fitness tests for this study are briefly discussed below. The anthropometrical measurements taken included body height and weight. The Body Mass Index (BMI) was calculated by dividing the weight by the square root of the height. Individuals were classified as obese if they had a BMI above the age and gender specific $85^{\text {th }}$ percentile. The BMI was dichotomized at the $85^{\text {th }}$ percentile because the researchers were interested in discovering what proportion of the learners was overweight. Systolic blood pressure (SBP) and diastolic blood pressure (DBP) were measured at rest in the sitting position with an electronic sphygmomanometer, which automatically recorded the pulse rate of the participant.

\section{Statistical analyses}

Statistical analyses were performed using SPSS 2000. Descriptive statistics of all the children were calculated for the relevant variables in the study. Risk factors were defined as obesity (BMI $>26)$, physical inactivity ( $<$ three and a half hours per week), smoking (current use in the past seven days), and hypertension ( $\mathrm{SBP}>130$; $\mathrm{DBP}>85)$. Variance of analysis (ANOVA) was used to statistically determine differences in groups. A p-value of $<0.05$ was accepted as a statistical difference between groups.

\section{RESULTS AND DISCUSSION}

From the total number of learners (951), at least $21 \%$ were identified as engaging in health risk behaviours that could become risk factors for chronic diseases of lifestyle. Of the 951 
participants, $32 \%$ did not meet the requirement of participating in physical activity for three and a half hours per week ( $3.5 \mathrm{~h} /$ week) to be classified as being active. The mean time of participants who participated in moderate and vigorous activity was $2.8 \mathrm{~h} /$ week and 4.16 $\mathrm{h} /$ week respectively. Table 1 indicates the overall prevalence of cigarette use and alcohol drinking among the learners who were classified as being physically active and those classified as being physically inactive.

TABLE 1: HEALTH PROFILE OF THE HEALTH RISK BEHAVIOURS OF THE LEARNERS

\begin{tabular}{|ll|c|l|}
\hline Variable & & Active learners $(\mathbf{N}=\mathbf{6 4 4})$ & Inactive learners $(\mathbf{N}=\mathbf{3 0 7})$ \\
\hline \multirow{2}{*}{ Gender } & Male & $342(53 \%)$ & $135(44 \%)$ \\
& Female & $302(47 \%)$ & $172(56 \%)$ \\
Age & 13 & $83(13 \%)$ & $45(15 \%)$ \\
& 14 & $194(30 \%)$ & $68(22 \%)$ \\
& 15 & $146(23 \%)$ & $47(15 \%)$ \\
& 16 & $97(15 \%)$ & $65(21 \%)$ \\
& 17 & $69(10 \%)$ & $50(16 \%)$ \\
\multirow{5}{*}{ Smoking } & $55(9 \%)$ & $126(41 \%)$ \\
& 18 & $201(31 \%)$ & $181(59 \%)$ \\
Desinking & Yes & $443(69 \%)$ & $137(45 \%)$ \\
& No & $138(21 \%)$ & $170(55 \%)$ \\
& No & $506(79 \%)$ & \multicolumn{2}{l}{}
\end{tabular}

Various studies have indicated that smoking is associated with less physical activity and regular physical activity with non-smoking (Yang et al., 1999). In addition, smoking is responsible for about two million deaths a year (Peto et al., 1994). In some calculations it is estimated that smoking reduces the life expectancy of a 20 -year-old person by 4.3 years (Manning et al., 1991). It is also well documented that cigarette smoking substantially increases the risk of cardiovascular disease, including stroke, heart attack, peripheral vascular disease and aortic aneurysm (USDHHS, 1996; Bartecchi et al., 1994).

One hundred and thirty-seven of the physically inactive high school learners reported that they had drunk alcohol in the previous week. Further analysis found that $21 \%$ of the physically inactive learners both smoked cigarettes and drank alcohol. Pearson's Chi-Square showed that the older learners were more likely to participate in smoking and drinking $(\mathrm{p}<0.05)$. A similar study by De Bourdeaudhuij and Oost (1999) found a high correlation with physical activity in the over 16 year age group for smoking and alcohol consumption.

It can thus be seen that a large number of the learners in this community were at risk of developing chronic diseases of lifestyle, as $31 \%$ of them were physically inactive and of these physically inactive learners, $21 \%$ were engaging in health risk behaviours such as smoking and drinking alcohol. 


\section{Anthropometric measurements and physical activity participation}

The average BMI for the participants was 20.8. The average BMI at the $95^{\text {th }}$ percentile for being overweight was 26.2 . Approximately $23 \%$ of the participants fell into this category and were thus classified as being overweight. Of the overweight participants, $18 \%$ were male in comparison to the $27 \%$ females. Cross-tabulations and ANOVA tables indicated that the relationship between $\mathrm{BMI}$ and gender $(\mathrm{df}=1 ; \mathrm{F}=28.43 ; \mathrm{p}<0.00)$ and the relationship between $\mathrm{BMI}$ and age $(\mathrm{df}=5 ; \mathrm{F}=5.32 ; \mathrm{p}<0.00)$ were statistically significant.

The overall prevalence of hypertension was $15 \%$, with males accounting for $14 \%$ and females accounting for $15 \%$. Table 2 presents an overall picture of the learners' physiological measurements with regard to obesity and high blood pressure.

\section{TABLE 2: DESCRIPTION OF LEARNERS' PHYSIOLOGICAL MEASUREMENTS WITH REGARD TO OBESITY AND INCREASED BLOOD PRESSURE}

\begin{tabular}{|ll|c|l|}
\hline \multicolumn{2}{|l|}{ Variable } & $\begin{array}{l}\text { Active learners } \\
(\mathbf{n = 6 4 4 )}\end{array}$ & $\begin{array}{l}\text { Inactive learners } \\
(\mathbf{n}=\mathbf{3 0 7})\end{array}$ \\
\hline \multirow{2}{*}{ BMI } & Normal & $510(79 \%)$ & $220(72 \%)$ \\
& Underweight & $14(5 \%)$ & $73(24 \%)$ \\
& Overweight & $547(16 \%)$ & $234(76 \%)$ \\
SBP & Normal & $58(9 \%)$ & $37(12 \%)$ \\
& Stage1 hypertension & $39(6 \%)$ & $36(12 \%)$ \\
& Stage 2 hypertension & $526(82 \%)$ & $224(73 \%)$ \\
DBP & Normal & $65(10 \%)$ & $50(16 \%)$ \\
& Stage1 hypertension & $53(8 \%)$ & $33(11 \%)$ \\
& Stage 2 hypertension & &
\end{tabular}

The clinical significance of overweight and obesity in adolescent populations is a public health concern. Adolescents who are overweight have increased average blood pressures, heart rates and cardiac outputs compared to their non-overweight peers (Moran, 1999).

Of the 307 (32\%) physically inactive high school learners, $73(23.8 \%)$ were overweight and $126(41 \%)$ smoked. In addition, $83(27 \%)$ of the physically inactive high school learners were hypertensive. Risk appraisals have been developed to quantify an individual's susceptibility to chronic heart disease. The following risk factors for chronic heart disease are commonly recognised: cigarette smoking ( $>10$ per day), physical inactivity, hypertension and obesity as well as hyper-cholesterolaemia. According to McArdle et al. (1996), the interaction of three or more of these risk factors in an individual magnifies their effects. Table 3 gives a profile of risk factors of learners in the study. Of the learners who participated in the study, $21 \%$ had two or more risk factors, $10 \%$ had three or more risk factors and $4 \%$ had four risk factors. 
TABLE 3: MULTIPLE MODIFIABLE RISK FACTOR PROFILE (N=951)

\begin{tabular}{|ll|}
\hline Number of risk factors present & \% of learners \\
\hline Physical inactivity & 32 \\
Physical inactivity and smoking & 21 \\
Physical inactivity, smoking and obesity & 10 \\
Physical inactivity, smoking, obesity and hypertension & 4 \\
\hline
\end{tabular}

From the current study it can be seen that a substantial number of these learners are at risk of developing chronic diseases of lifestyle. The risk factors identified in the literature have been identified in these learners, namely obesity, high blood pressure and inadequate fitness levels. It is important to accumulate evidence regarding adolescent health-related physical fitness, as it assists health professionals in identifying young people at risk, thus allowing for early intervention.

\section{CONCLUSION}

More than one risk factor was present in $21 \%$ of the learners in this study, thus predisposing them to an early development of certain chronic diseases. Baranowski et al., (1992) indicated that most children tend to have at least one risk factor for cardiovascular disease which has practical implications for health promotion programmes. Since cardiovascular risk factors have been shown to persist into adulthood, this may translate into an epidemic of cardiovascular disease in the adults in this community in the future. The conclusion that can be made from the results is that physical inactivity in association with other health risk behaviours such as smoking, drinking alcohol, obesity and hypertension should be considered a public health concern in this community. Thus it is concluded that primary prevention and intervention through risk factor modification can be effective in childhood. Health professionals should thus assume some responsibility for the prevention, detection, and intervention relevant to cardiovascular risk factors in adolescents. Promotion of a healthy lifestyle, including regular physical activity and avoidance of risky behaviours, should be incorporated into health maintenance encounters. Adolescents should be empowered through education and skills development to assume increasing responsibility for their own health behaviours. Although the expense and the duration of follow-up studies prohibit longitudinal studies to document that altering cardiovascular risk factors in childhood will reduce morbidity and mortality from this disease in adulthood, it is intuitive to suppose that risk factor modification early in life will have a positive impact.

\section{ACKNOWLEDGEMENT}

The following people are gratefully acknowledged: Vlaamse Inter-universitêre Raad (VLIR) funding and the University of the Western Cape. 


\section{REFERENCES}

ALBERTI, G. (2001). Noncommunicable diseases: tomorrow's pandemics. Editorial. Bulletin of the World Health Organisation, 79(10): 907.

BARANOWSKI, T. (1988). Validity and reliability of self-report measures of physical activity: an information-processing perspective. Research Quarterly for Exercise and Sport, 59: 314-327.

BARANOWSKI, T.; BOUCHARD, C.; BAR-OR, O.; BRICKER, T.; HEATH, G.; KIMM, S.; MALINA, R.; OBARZANEK, E.; PATE, R.; STRONG, W.; TRUMAN, B. \& WASHINGTON, R. (1992). Assessment, prevalence and cardiovascular benefits of physical activity and fitness in youth. Medicine and Science in Sports and Exercise, 24(suppl): S237-S247.

BARTECCHI, C.E.; MACKENZIE, T.D. \& SCHRIER, R.W. (1994). The human costs of tobacco use. New England Journal of Medicine, 330: 907-912.

BAUMAN, A. \& CAMPBELL, T. (2001). Heart Week 2001: Get Active! A call to action. Medical Journal of Australia, 174: 381-382.

BIRTH TO TWENTY STUDY (2002). Physical activity and South African children - some shocking findings. March 2002. Study Updates.

BOUCHARD, C.; SHEPHARD, R.; STEPHENS, T. \& McPHERSON, B. (1990). Exercise, fitness and health: the consensus statement. In C. Bouchard; R. Shephard; T. Stephens \& B.D. McPherson (Eds.). Exercise, fitness and health: a consensus of current knowledge (3-28). Champaign, IL: Human Kinetics.

BRUNTON, G.; HARDEN, A.; REES, R.; KAVANAGH, J.; OLIVER, S. \& OAKLEY, A. (2003). Children and physical activity: a systematic review of barriers and facilitators. London. EPPICentre, Social Science Research Unit, Institute of Education, University of London.

CANON, G. (2001). Health and nutrition emerging and re-emerging issues in developing countries. International Food Policy Research Institute, Focus 5, Brief 8(11): 1-4.

CENTER FOR DISEASE CONTROL AND PREVENTION (1996). Report for the Surgeon General. Physical Activity and Health. Atlanta, GA: US Department of Health and Human Services.

COETZEE, M. \& UNDERHAY, C. (2003). Gesondheidsrisikogedrag by adolessente van verskillende ouderdomme. Suid-Afrikaanse Tydskrif vir Navorsing in Sport, Liggaamlike Opvoedkunde en Ontspanning, 25(2): 27-36.

DE BOURDEAUDHUIJ, I. \& OOST, P. (1999). A cluster-analytical approach toward physical activity and other health related behaviours. Medicine and Science in Sports and Exercise, 31: 605-612.

KATZMARZYK, P.; MALINA, R.; SONG, T. \& BOUCHARD, C. (1998). Physical activity and healthrelated fitness in youth: a multivariate analysis. Medicine and Science in Sport and Exercise, 30(5): 709-714.

LAMBERT, E.V.; BOHLMANN, I. \& KOLBE-ALEXANDER, T. (2001). "Be active" - physical activity for health in South Africa. South African Journal of Clinical Nutrition, 14(3): S12-S16.

MANNING, W.; KEELER, E.B.; NEWHOUSE, J.P.; SLOSS, E.M. \& WASSERMAN, J. (1991). The costs of poor health habits. Cambridge, MA: Harvard University Press.

McARDLE, D.; KATCH, F. \& KATCH, V. (1996). Exercise Physiology ( $3^{\text {rd }}$ ed.). Philadelphia, PA: Lea and Febiger.

MORAN, R. (1999). Evaluation and treatment of childhood obesity. American Family Physician, 59(4): 861-877.

PETO, R.; LOPEZ, A.D.; BOREHAM, J.; THUN, M. \& HEATH, C. (1994). Mortality from smoking in developed countries 1950-2000. Indirect estimates from national vital statistics. New York, NY: Oxford University Press.

SURGEON GENERAL REPORT (1996). Physical activity and health: a report of the Surgeon General. Atlanta, GA: US Department of Health and Human Services, Centres for Disease Control and Prevention, National Center for Chronic Disease Prevention and Health Promotion. 
UNDERHAY, C.; DE RIDDER, J.H.; VAN ROOYEN, J.H. \& KRUGER, H.S. (2003). The effect of urbanization on the relationship between physical activity and obesity in 10-15 year old males in the North West province of South Africa: Thusa Bana study. South African Journal for Research in Sport, Physical Education and Recreation, 25(2): 77-92.

UNITED STATES DEPARTMENT OF HEALTH AND HUMAN SERVICES (USDHHS) (1996). Physical activity and health: a report of the Surgeon General. Atlanta, GA: US Department of Health and Human Services, Centres for Disease Control and Prevention, National Center for Chronic Disease Prevention and Health Promotion.

WORLD HEALTH ORGANISATION (2003). Surveillance of risk factors for noncommunicable diseases. The WHO STEPwise approach. Geneva: World Health Organisation.

WORLD HEALTH REPORT (2000). Health Systems: Improving performance. Geneva: World Health Organisation.

YANG, X.; TELAMA, R. \& LEINO, M. (1999). Factors explaining the physical activity of young adults: the importance of early socialization. Scandanavian Journal of Medicine and Science in Sports, 9: 371-378.

Prof. José M. Frantz: Department of Physiotherapy, University of the Western Cape, Private Bag X17, Bellville 7535, Republic of South Africa. Tel: +27 (0)21 959 2542, Fax: +27 (0)21 959 1217, Email: jfrantz@uwc.ac.za

(Subject editor: Prof. J.G. Barnard) 